\title{
IDENTIFIKASI BENTUK PEMBINAAN SEKOLAH TERHADAP SISWA DENGAN PERILAKU JUVENILE DELINQUENSI
}

\author{
Yakub Nasucha $^{1}$, Dini Restiyanti Pratiwi ${ }^{2}$, Atiqa Sabardila ${ }^{3}$ \\ PBI - FKIP Universitas Muhammadiyah Surakarta \\ MPBI Universitas Muhammadiyah Surakarta \\ Surel: yakub.nasucha@ums.ac.id
}

Submitted: 2018-10-29

Accepted: 2019-07-10

Published: 2019-08-27

\begin{tabular}{ll}
\hline Keywords: & Abstract \\
\hline Coaching, & This study aimed to identify models of coaching conducted by \\
Prevention, & schools in dealing with the deviant behavior of adolescent of high \\
Deviant & school students. Data in this study were collected through written \\
behavior, & interviews. Written interviews were conducted for first semester \\
Juvenile & students of the Indonesian Education, Teacher Training and \\
delinquency & Education Faculty, UMS. They were just graduated from high \\
& school with experience as observers and / or juvenile delinquents \\
& that occurred in school. In addition, interviews were also conducted \\
& with senior high school counseling teachers in Surakarta. This \\
& written interview was conducted in snowball which was then \\
& analyzed by content analysis. The results showed that there were 7 \\
& models in coaching that the school carried out, namely: (1) giving \\
& advice, (2) giving motivation, (3) giving guidance and calling on \\
& guardians of students, (4) socializing the introduction of the school \\
& environment during MOS, (5) penalties adjusted for the type of \\
& violation, (6) basic leadership training, and (7) home visit. The \\
& form of guidance given is adjusted to the violations committed by \\
& students.
\end{tabular}

\section{PENDAHULUAN}

Pakar pendidikan telah melakukan banyak kajian terhadap kurikulum, strategi pembelajaran, media pembelajaran, hingga bahan ajar dalam pembelajaran. Kajian tersebut dilakukan semata-mata untuk meningkatkan kualitas pendidikan sehingga mampu menjalankan amanat dalam UU No. 20 tahun 2003 tentang Sistem Pendidikan Nasional Bab II pasal 3 yang menyatakan bahwa pendidikan nasional memiliki fungsi untuk mengembangkan kemampuan, membentuk watak, dan peradaban bangsa yang bermartabat dalam rangka mencerdaskan kehidupan bangsa.

Selain itu, tujuan pendidikan nasional adalah mengembangkan potensi siswa sehingga menjadi manusia yang beriman dan bertakwa kepada Tuhan Yang Maha Esa, berakhlak mulia, berilmu, sehat, cakap, kreatif, mandiri, serta mampu menjadi warga negara yang demokratis dan bertanggung jawab. 
Usaha yang dilakukan untuk menciptakan siswa menjadi manusia yang cakap dan kreatif tentu tidak cukup hanya mengandalkan ilmu pengetahuan. Akan tetapi, ilmu pengetahuan yang dikuasai haruslah seimbang dengan sikap dan keterampilan yang dimiliki. Oleh karena itu, siswa sebagai subjek pendidikan perlu diarahkan untuk memiliki karakter serta perilaku yang baik sebagai modal untuk belajar dan mengembangkan potensi. Usaha ini dapat diintegrasikan dalam proses pembelajaran baik melalui strategi yang digunakan maupun materi ajar yang diberikan.

Perkembangan kurikulum saat ini telah mengakomodasi penguatan karakter dan perilaku bagi siswa melalui kerangka dasar dan struktur kurikulum dengan mengelompokkan jenis kompetensi ke dalam empat kelompok. Keempat kompetensi tersebut meliputi kompetensi inti mengenai sikap spiritual, sosial, pengetahuan, dan keterampilan. Hal ini dilakukan sebagai salah satu upaya untuk mencegah munculnya perilaku menyimpang atau kenakalan pada siswa.

Perilaku menyimpang yang dilakukan oleh siswa merupakan perilaku patologi sosial yang diakibatkan oleh pengabaian terhadap norma-norma sosial. Kartono (2001:1) menyebutkan bahwa patologi sosial merupakan penyakit sosial murni dengan ukuran moralistik. Lebih rinci dijelaskan bahwa patologi sosial adalah semua tingkah laku yang bertentangan dengan norma kebaikan, stabilitas lokal, pola kesederhanaan, moral, hak milik, solidaritas kekeluargaan, hidup rukun bertetangga, disiplin, kebaikan, dan hukum formal. Aspek-aspek perilaku menyimpang menurut Kartono (2001:13) dapat dibedakan menjadi dua, yakni aspek lahiriah yang muncul dalam bentuk verbal dan nonverbal serta aspek simbolik yang tersembunyi mencakup sikap hidup, emosi, sentiment, dan motivasi yang mengembangkan tingkah laku menyimpang.

Siswa yang menjadi subjek dalam penelitian ini merupakan siswa dengan tingkat pendidikan sekolah menengah atas (SMA). Siswa pada tingkat ini umumnya berusia antara 15 hingga 17 tahun sehingga dapat digolongkan dalam kategori remaja. Hal ini mengacu pada penyataan Yusuf (2011:184) yang menyatakan bahwa fase remaja merupakan segmen perkembangan individu yang diawali dengan matangnya organorgan fisik (seksual) sehingga mampu bereproduksi. Masa remaja dimulai saat seseorang berusia 12 hingga 22 tahun. Perilaku menyimpang pada remaja biasa disebut dengan juvenile delinquency atau kenakalan remaja.

Pada fase perkembangan remaja masa remaja merupakan pusat perhatian. Menurut Willis (2012:19) masa remaja merupakan masa transisi dari masa kanak-kanak ke dewasa. Pada masa inilah seseorang membutuhkan sebuah eksistensi dan penghargaan dari orang-orang di sekitarnya. Apabila penghargaan yang muncul tidak sesuai dengan harapan, maka akan muncul perilaku juvenile delinquency.

Sekolah sebagai rumah kedua bagi siswa dengan guru-guru yang membimbing dan komponen yang ada di dalamnya tentu direncanakan dan didesain sebaik mungkin untuk memberikan teladan yang baik bagi siswanya. Pihak sekolah menyediakan berbagai solusi untuk menyelesaikan permasalahan yang dihadapi siswa baik secara akademik maupun nonakademik. Namun demikian, sering kali solusi yang ditawarkan tidak dapat dilaksanakan secara efektif dan optimal yang disebabkan oleh keterbatasan tertentu.

Penelitian ini berfokus pada permasalahan apa saja bentuk pembinaan yang diberikan sekolah kepada siswa yang berperilaku patologi (juvenile delinquensi)? Selanjutnya penelitian ini memiliki tujuan mengidentifikasi bentuk pembinaan yang selama ini telah dilakukan sekolah untuk menangani perilaku patologis siswa sekolah menengah atas di Jawa Tengah. 
Yakub Nasucha, Dini Restiyanti Pratiwi, dan Atiqa Sabardila, Identifikasi Bentuk Pembinaan ...

\section{METODE}

Penelitian ini merupakan penelitian kualitatif dengan teknik pengumpulan data wawancara tertulis. Wawancara tertulis dilakukan kepada mahasiswa baru program studi Pendidikan Bahasa Indonesia, Fakultas Keguruan dan Ilmu Pendidikan, Universitas Muhammadiyah Surakarta saat berada di semester 1. Mahasiswa baru merupakan alumni yang baru saja lulus dari SMA dengan pengalaman sebagai pengamat dan atau juga pelaku kenakalan remaja yang terjadi di sekolah. Selain itu, wawancara juga dilakukan kepada guru bimbingan konseling sekolah menengah atas yang ada di Surakarta. Wawancara tertulis ini dilakukan secara snowball yang selanjutnya dianalisis dengan analisis isi (content analysis).

\section{HASIL DAN PEMBAHASAN}

Sekolah sebagai tempat dalam melaksanakan pendidikan yang bersifat formal, memiliki keunggulan dibandingkan dengan jenis pendidikan informal dan nonformal. Salah satu keunggulan yang diberikan dalam pendidikan secara formal adalah menyajikan pembelajaran yang lebih luas, lebih tinggi, dan lebih dalam. Dalam hal ini aktivitas pembelajaran dalam pendidikan formal tidak melulu berkaitan dengan materi dan pengetahuan, melainkan juga mengembangkan sikap dan keterampilan siswa. Oleh karena itu, sekolah tidak hanya berperan sebagai tempat untuk memperoleh pengetahuan, tetapi juga mengembangkan sikap baik sikap spiritual dan sosial serta keterampilan peserta didik. Berkaitan dengan hal ini, sekolah memiliki peran dalam membina peserta didik untuk menjadi pribadi yang berkualitas, beriman, dan bertaqwa tidak hanya melalui aktivitas pembelajaran, tetapi juga di luar itu.

Setiap sekolah tentu memiliki regulasi yang harus ditaati bersama mulai dari guru, karyawan hingga siswanya untuk menciptakan karakter sekolah yang unggul. Berbagai bentuk pembinaan dalam rangka membentuk sikap positif siswa dilakukan untuk mencegah perilaku menyimpang yang dilakukan siswa. Berikut ini tersaji identifikasi bentuk pembinaan yang dilakukan oleh sekolah menengah atas dalam mencegah perilaku menyimpang siswanya.

Berdasarkan Tabel 1, diketahui bahwa terdapat variasi upaya pembinaan yang dilakukan sekolah dalam mencegah perilaku menyimpang pada siswa, di antaranya (1) pemberian nasihat, (2) pemberian motivasi, (3) pemberian pengarahan dan memanggil wali murid, (4) sosialisasi pengenalan lingkungan sekolah saat MOS, (5) hukuman yang disesuaikan dengan jenis pelanggaran, (6) diberi pelatihan dasar kepemimpinan, dan (7) dilakukan home visiting. Dari 16 sekolah diketahui aktivitas latihan dasar kepemimpinan bagi siswa dan home visiting hanya dilakukan oleh 1 sekolah saja. Dari 6 jenis upaya yang dilakukan sekolah yang paling umum dilakukan adalah pemberian nasihat dan motivasi kepada siswa sebagai upaya mencegah perilaku menyimpang. Berikut deskripsi mengenai upaya pembinaan yang dilakukan sekolah untuk mencegah perilaku menyimpang pada siswanya. 
Tabel 1. Identifikasi Bentuk Pembinaan Sekolah dalam Mencegah Perilaku

Menyimpang Siswa SMA

\begin{tabular}{|c|c|c|c|c|c|c|c|c|}
\hline \multirow[t]{2}{*}{$\begin{array}{l}\mathbf{N} \\
\mathbf{0 .}\end{array}$} & \multirow[t]{2}{*}{ Inisial Sekolah } & \multicolumn{7}{|c|}{$\begin{array}{l}\text { Deskripsi Bentuk Pembinaan dari Sekolah Terhadap Penyimpangan } \\
\text { Perilaku Siswa }\end{array}$} \\
\hline & & $\begin{array}{c}\text { (1) } \\
\text { Diberi } \\
\text { Nasi } \\
\text { hat }\end{array}$ & $\begin{array}{c}\text { (2) } \\
\text { Diberi } \\
\text { Moti } \\
\text { vasi }\end{array}$ & $\begin{array}{c}(3) \\
\text { Diberi } \\
\text { pengarah } \\
\text { an dengan } \\
\text { memanggil } \\
\text { orang tua }\end{array}$ & $\begin{array}{c}(4) \\
\text { Sosiali } \\
\text { sasi } \\
\text { pengen } \\
\text { alan } \\
\text { lingkun } \\
\text { gan } \\
\text { sekolah } \\
\text { saat } \\
\text { MOS }\end{array}$ & $\begin{array}{c}\text { (5) } \\
\text { Diberi } \\
\text { hukum } \\
\text { an bila } \\
\text { melang } \\
\text { gar tata } \\
\text { tertib } \\
\text { sekolah }\end{array}$ & $\begin{array}{c}(6) \\
\text { Diberi } \\
\text { latihan } \\
\text { dasar } \\
\text { kepemi } \\
\text { mpinan }\end{array}$ & $\begin{array}{c}(7) \\
\text { Dilak } \\
\text { ukan } \\
\text { home } \\
\text { visit } \\
\text { ing }\end{array}$ \\
\hline 1. & SMA Negeri A & $\sqrt{ }$ & $\sqrt{ }$ & & & $\sqrt{ }$ & & \\
\hline 2. & MAN 1 B & & $\sqrt{ }$ & $\sqrt{ }$ & & & & \\
\hline 3. & SMK Negeri $1 \mathrm{C}$ & & & & & & & \\
\hline 4. & SMA Negeri $1 \mathrm{D}$ & $\sqrt{ }$ & $\sqrt{ }$ & & & & & \\
\hline 5. & SMA Negeri $1 \mathrm{E}$ & $\sqrt{ }$ & & & & & & \\
\hline 6. & SMA Negeri $1 \mathrm{~F}$ & & & & $\sqrt{ }$ & & & \\
\hline 7. & SMA Negeri $1 \mathrm{G}$ & & & & $\sqrt{ }$ & & & \\
\hline 8. & SMA Negeri $1 \mathrm{H}$ & $\sqrt{ }$ & $\sqrt{ }$ & & & & & \\
\hline 9. & SMA I & $\sqrt{ }$ & $\sqrt{ }$ & $\sqrt{ }$ & $\sqrt{ }$ & & & \\
\hline 10 & SMA Negeri $1 \mathrm{~J}$ & $\sqrt{ }$ & & & $\sqrt{ }$ & & & \\
\hline 11 & SMA Negeri K & $\sqrt{ }$ & $\sqrt{ }$ & & $\sqrt{ }$ & & & \\
\hline 12 & SMA Negeri $1 \mathrm{~L}$ & $\sqrt{ }$ & & & & & & \\
\hline 13 & SMA Negeri $2 \mathrm{M}$ & $\sqrt{ }$ & & & & & & \\
\hline 14 & SMK N & & & & $\sqrt{ }$ & & $\sqrt{ }$ & $\sqrt{ }$ \\
\hline 15 & SMA O & $\sqrt{ }$ & $\sqrt{ }$ & & & & & \\
\hline 16 & SMA Negeri P & $\sqrt{ }$ & $\sqrt{ }$ & & & $\sqrt{ }$ & & \\
\hline
\end{tabular}

\section{Upaya Pembinaan untuk Pencegahan Perilaku Menyimpang}

Pemberian Nasihat

Pemberian nasihat kepada siswa sebagai upaya mencegah perilaku menyimang menjadi upaya yang dilakukan oleh hampir seluruh sekolah. Dari 16 sekolah sebagai data dalam penelitian ini diketahui 12 di antaranya melakukan pembinaan pencegahan perilaku menyimpang siswa dengan memberikan pembinaan. Berdasarkan hasil wawancara pembinaan ini dilakukan secara rutin saat kepala sekolah memberikan sambutan upacara bendera hari senin. Berdasarkan hasil penelitian Prasetyo, dkk. (2013) dijelaskan bahwa pemberian nasihat merupakan salah satu bentuk pengendalian yang dilakukan oleh pihak sekolah untuk mengatasi perilaku menyimpang siswa. Pemberian nasihat ini, biasanya diberikan untuk jenis pelanggaran yang masih terbilang kecil.

\section{Pemberian Motivasi}

Berdasarkan 16 data, diketahui bahwa pemberian motivasi sebagai upaya dalam mencegah perilaku menyimpang pada siswa hampir dilakukan oleh seluruh sekolah yang meliputi 9 sekolahan. Pemberian motivasi dalam hal ini dilakukan dengan 
Yakub Nasucha, Dini Restiyanti Pratiwi, dan Atiqa Sabardila, Identifikasi Bentuk Pembinaan ...

menyampaikan kalimat-kalimat positif, menunjukkan dampak-dampak buruk yang diakibatkan perilaku menyimpang pada remaja, dan menunjukkan contoh-ontoh teladan yang berprestasi di lingkungan sekolah.

\section{Pemberian Pengarahan yang Didampingi oleh Wali Murid}

Perilaku menyimpang yang dilakukan oleh remaja dipengaruhi oleh faktor lingkungan dan faktor imitasi. Prasetyo, dkk. (2013) menyatakan bahwa faktor lingkungan dapat menjadi latar belakang mengapa anak berperilaku menyimpang. Faktor lingkungan dalam hal ini dibedakan menjadi dua, yaitu lingkungan yang berasal dari pertemanan sebagaya dan lingkungan yang berasal dari keluarga. Keluarga sebagai lingkungan pertama bagi siswa sangat berpengaruh terhadap pembentukan karakter siswa. Muladi (2007:48) menjelaskan bahwa faktor lingkungan seperti disharmoni hubungan dalam keluarga menjadi salah satu faktor remaja berperilaku menyimpang.

Selanjutnya, Trisnawati (2013) menjelaskan lemahnya pengawasan di rumah serta kurangnya kedisplinan menjadi salah satu faktor yang mempengaruhi bagaimana perilaku siswa di sekolah. Oleh karena itu, peranan orang tua sangatlah berpengaruh terhadap pembentukan karakter remaja.

\section{Pengenalan Lingkungan Sekolah saat Masa Orientasi Siswa (MOS)}

Pencegahan perilaku menyimpang pada siswa dapat dilakukan dengan pengenalan lingkungan sekolah saat MOS. Kegiatan ini diperuntukan tidak hanya untuk siswa, melainkan juga bagi orang tua. Hal ini dilakukan dengan tujuan orang tua mampu memahami bagaimana lingkungan sekolah dan mendukung penciptaan lingkungan positif di luar sekolah. Trisnawati (2013) menjelaskan bahwa komunikasi antarwarga sekolah adalah salah satu upaya dalam membentuk karakter disiplin siswa. Dalam hal ini warga sekolah tidak hanya siswa dan guru, melainkan melibatkan peran orang tua di dalamnya. Komunikasi antarwarga sekolah ini dapat berlangsung saat kegiatan MOS dengan menyosialisasikan tata tertib dan budaya sebagai bagian dari aktivitas di lingkungan sekolah.

\section{Pemberian Hukuman yang Sesuai dengan Jenis Pelanggaran}

Pembinaan yang dilakukan oleh sekolah dalam mencegah perilaku menyimpang siswa semata-mata dilaksanakan dengan tujuan membangun karakter siswa dan kedisplinan siswa. Hal ini dilakukan untuk mewujudkan karakter yang unggul dengan displin dan tanggung jawab yang tinggi. Dalam upaya mewujudkan disiplin yang tinggi sekolah memberikan punishment (hukuman) dan reward (penghargaan) atas segala tindakan yang dilakukan oleh siswa. Sistem reward dan punishment ini juga diterapkan di SMA Kadhijah Surabaya dalam penelitian Trisnawati (2013).

Hasil penelitian Trisnawati menjelaskan bahwa siswa dengan berbagai sikapnya dalam rangka membentuk karakter yang displin dan tanggung jawab perlu diberikan konsekuensi-konsekuensi atas segala perilakunya agar dapat berubah. Berubah merupakan salah satu ciri-ciri pembelajaran yang berhasil. Apabila perilaku yang dimunculkan adalah perilaku yang dapat diteladani, maka siswa mendapatkan pujian atau penghargaan agar terus meningkatkan perilaku tersebut dan memotivasi siswa lainnya untuk ikut meneladani. Adapun apabila perilaku yang dimunculkan merupakan perilaku menyimpang, maka siswa harus diberi hukuman agar jera dan mau mengubah perilaku. 


\section{Pemberian Latihan Dasar Kepemimpinan}

Latihan dasar kepemimpinan merupakan salah satu upaya dalam mencegah perilaku menyimpang pada siswa. Kegiatan latihan kepemimpinan dasar ini dilakukan dalam bentuk kegiatan ekstrakurikuler. Menurut Fitriani dan Suyanto (2015) latihan kepemimpinan dasar diterapkan kepada siswa untuk mengembangkan karakter kepemimpinan sehingga siswa mampu mencapai karakter lainnya seperti disiplin, tanggung jawab, dan jujur. Latihan kepemimpinan dasar diberikan sebagai upaya mencegah perilaku menyimpang di SMK N di samping pengenalan lingkungan sekolah yang meliputi tata tertib dan budaya sekolah serta home visit.

Latihan kepemimpinan dasar di sekolah SMK $\mathrm{N}$ termasuk dalam kegiatan ekstrakurikuler yang artinya belum seluruh siswa diwajibkan mengikuti kegiatan tersebut sehingga memungkinkan siswa yang ikut bukanlah siswa yang bermasalah dan memiliki perilaku menyimpang.

\section{Home Visit}

Kunjungan (ke) rumah (home visit) yang diterapkan sekolah untuk mencegah dan mengatasi perilaku menyimpang pada remaja dilakukan oleh SMK N. Namun demikian, berdasarkan wawancara diketahui bahwa penyelenggaraan home visit ini juga memiliki kendala, salah satunya sulitnya bertemu orang tua secara langsung pada jam dan hari sekolah. Hal ini dikarenakan banyak orang tuas siswa yang bekerja. Penerapan kunjungan (home visit) akhirnya menjadi bentuk pembinaan yang dilakukan sekolah apabila permasalahan yang dialami siswa sudah terlalu berat.

Dhiada (2015) menjelaskan bahwa home visit dalam dunia pendidikan penting untuk diterapkan program ini bertujuan untuk orang tua lebih memahami bagaimana kondisi dan perilaku anak di sekolah. Begitu pula sebaliknya, guru dapat lebih memahami kondisi siswa dengan mengamati secara langsung latar belakang kehidupan keluarga siswa yang bersangkutan.

Berdasarkan deskripsi mengenai bentuk pembinaan yang dilakukan sekolah untuk menangani serta mencegah perilaku menyimpang pada remaja (juvenile delinquensi) nampak bahwa bentuk pembinaan yang diberikan disesuaikan dengan pelanggaran yang dilakukan siswa. Namun demikian, pembinaan juga dilakukan sebagai upaya pencegahan, artinya tidak selalu hanya berlangsung saat pelanggaran terjadi namun juga dilakukan untuk mencegah perilaku-perilaku menyimpang itu muncul, seperti pemberian nasihat atau motivasi yang disisipan kepala sekolah pada setiap kali upacara bendera.

\section{SIMPULAN}

Sekolah merupakan salah satu tempat bagi siswa dalam mengembangkan karakter yang unggul. Karakter unggul dapat berupa karakter disiplin, tanggung jawab, dan jujur. Selain itu, sekolah bertanggung jawab dalam mencetak siswa yang berkarakter unggul, beriman, dan bertaqwa. Oleh karena itu, sekolah memiliki regulasi dalam memberikan penghargaan dan hukuman kepada siswa. Dalam menangani perilaku siswa yang menyimpang, setiap sekolah memiliki cara sendiri yang bervariasi untuk menyelesaikannya. Berdasarkan identifikasi terhadap bentuk pembinaan dalam menanngani perilaku menyimpang siswa dapat disimpulkan terdapat 7 variasi bentuk pembinaan yang meliputi (1) pemberian nasihat, (2) pemberian motivasi, (3) pemberian pengarahan dan memanggil wali murid, (4) sosialisasi pengenalan lingkungan sekolah saat MOS, (5) hukuman yang disesuaikan dengan jenis pelanggaran, (6) diberi pelatihan dasar kepemimpinan, dan (7) dilakukan home visit. 
Yakub Nasucha, Dini Restiyanti Pratiwi, dan Atiqa Sabardila, Identifikasi Bentuk Pembinaan ...

\section{DAFTAR PUSTAKA}

Dhiada, R. (2015). Keterlibatan orang tua dalam pendidikan anak usia dini di taman kanak-kanak. Edusentris (Jurnal Ilmu Pendidikan dan Pengajaran), 2 (1): 6171.

Fitriani, E. S. dan Suyanto, T. (2015). Kompetensi kepemimpinan siswa pasca mengikuti program latihan dasar kepemimpinan siswa di SMK Negeri 12 Surabaya. Jurnal Kajian Moral dan Kewarganegaraan, 3 (3): 1360-1367.

Kartono, K. (2001). Patologi sosial jilid 1 edisi baru. Jakarta: Raja Grafindo Persada. . (2002). Patologi sosial 2 kenakalan remaja. Jakarta: Raja Grafindo Persada.

Muladi, Y. (2007). "Fenomena perilaku menyimpang remaja". http://jurnal.pdii.lipi.go.id/admin/jurnal/69074351.

Prasetyo, H. dkk. (2013). "Pengendalian perilaku menyimpang siswa SMP di Madrasah Tsnawiyah Al-Ishlah Baitil Mal Pontianak". Jurnal Pendidikan dan Pembelajaran, 2 (7). 70-82.

Trisnawati, D.(2013). Membangun disiplin dan tanggung jawab siswa SMA Khadijah Surabaya melalui implementasi tata tertib sekolah. Jurnal Kajian Moral dan Kewarganegaraan, 2 (1): 397-411.

Undang-undang No. 20 Tahun 2003 tentang Sistem Pendidikan Nasional.

Willis, S. (2012). Remaja dan masalahnya (mengupas berbagai bentuk kenakalan remaja narkoba, free sex, dan pemecahannya. Bandung: Alfabeta.

Yusuf, S. (2011). Psikologi perkembangan anak dan remaja. Bandung: Remaja Rosdakarya.. 